06;09

\title{
Исследование влияния структурных дефектов на спектры фотолюминесценции в $n-3 C$-SiC
}

\author{
(C) А.А. Лебедев ${ }^{1,2}$, И.П. Никитина ${ }^{1}$, Н.В. Середова ${ }^{1}$, Н.К. Полетаев ${ }^{1}$, С.П. Лебедев ${ }^{1}$ \\ В.В. Козловский ${ }^{3}$, А.В. Зубов \\ ${ }^{1}$ Физико-технический институт им. А.Ф. Иофрфе РАН, Санкт-Петербург, Россия \\ ${ }^{2}$ Санкт-Петербургский государственный электротехнический университет „ЛЭТИ“, Санкт-Петербург, Россия \\ ${ }^{3}$ Санкт-Петербургский политехнический университет Петра Великого, Санкт-Петербург, Россия \\ ${ }^{4}$ Санкт-Петербургский национальный исследовательский университет информационных технологий, механики и оптики \\ (Университет ИТМО), Санкт-Петербург, Россия \\ E-mail: shura.lebe@mail.ioffe.ru
}

Поступило в Редакцию 25 февраля 2019г.

В окончательной редакции 14 марта 2019г.

Принято к публикации 14 марта 2019г.

Проведено исследование спектров фотолюминесценции в гетероструктурах $3 C$-SiC/4H-SiC и монокристаллах $3 C$-SiC. Показано, что эпитаксиальные слои $3 C$ - $\mathrm{SiC}$, выращенные на подложках $4 H-\mathrm{SiC}$, имеют существенно меньшее структурное совершенство, чем монокристаллы $3 C$-SiC. Обнаружено, что легирование алюминием приводит к появлению характерной фотолюминесценции как в эпитаксиальных слоях, так и в монокристаллах $3 \mathrm{C}$-SiC. B то же время облучение электронами эпитаксиальных слоев не приводит к появлению „дефектной“ фотолюминесценции, как это наблюдается для монокристаллов. Высказано предположение, что существующие в эпитаксиальных слоях $3 C$-SiC двойниковые границы могли служить геттерами радиационных дефектов, являющихся компонентами донорно-акцепторных пар, ответственных за „дефектную“ фотолюминесценцию.

Ключевые слова: фотолюминесценция, кубический политип карбида кремния, сублимационная эпитаксия, облучение электронами.

$3 C-\mathrm{SiC}$ - единственный кубический политип карбида кремния - является перспективным материалом для создания различных полупроводниковых приборов, в том числе и с гетеропереходами $[1,2]$. Он обладает максимальной среди политипов $\mathrm{SiC}$ подвижностью носителей заряда, которая не зависит от кристаллического направления, при этом его остальные электрофизические параметры практически не уступают параметрам наиболее разработанных политипов $4 H$ - и $6 H$-SiC.

Проблемой является отсутствие подложек $3 C-\mathrm{SiC}$ большого размера. Существующая технология позволяет получать монокристаллы размером несколько кубических миллиметров [3]. Поэтому основным методом изготовления $3 C$ - $\mathrm{SiC}$ большой площади является его гетероэпитаксия на основе подложек кремния [4] либо гексагональных политипов $\mathrm{SiC}[5,6]$. В обоих случаях пленки $3 C$ - $\mathrm{SiC}$ обладают большой плотностью структурных дефектов. При этом в пленках $3 C$ - $\mathrm{SiC}$, выращенных на кремнии, преобладают равномерно распределенные по объему пленки дислокации. При росте кубического эпитаксиального слоя на гексагональном $\mathrm{SiC}$ зародышеобразование начинается одновременно в разных точках (местах) гексагональной подложки, при этом имеет место ориентация зародышей $3 C$-SiC вдоль поверхности роста двух видов, которые различаются разворотом относительно друг друга на $60^{\circ}$ (двойниковая структура). В итоге структурные дефекты сосре- доточены на границах двойников $3 C$-SiC, образующих дефектные области (double position boundaries, DPB).

Таким образом, изучение влияния структурных дефектов на различные свойства пленок $3 C$-SiC представляется важной исследовательской задачей. В настоящей работе рассмотрено влияние структурных дефектов на две типичные полосы фотолюминесценции (ФЛ) в $\mathrm{SiC}-$ связанные с примесью алюминия и с радиационными дефектами.

Известно, что изменение соотношения $\mathrm{Si}: \mathrm{C}$ в зоне роста оказывает существенное влияние на гетерополитипную эпитаксию карбида кремния. Так, увеличение концентрации $\mathrm{Si}$ приводит к увеличению вероятности образования $3 C$ - $\mathrm{SiC}$. Рост слоев $3 C-\mathrm{SiC}$ на основе подложек гексагонального $\mathrm{SiC}$ возможен также при сублимационной эпитаксии в избытке кремния $[7,8]$.

Исследуемые структуры были выращены методом сублимационной эпитаксии в вакууме (SEV) на подложке (0001)Si грани 4H-SiC. Температура роста составляла $1950-2000^{\circ} \mathrm{C}$, а время роста $-10 \mathrm{~min}$, площадь выращенного слоя $3 C-\mathrm{SiC} \sim 1 \mathrm{~cm}^{2}$. В качестве источника использовался коммерческий мелкозернистый порошок карбида кремния с диаметром зерна 10-20 $\mu \mathrm{m}$. Были выращены как нелегированные слои, так и слои, легированные в процессе роста алюминием.

Для возбуждения ФЛ использовался азотный лазер, работающий на длине волны $325 \mathrm{~nm}$ и имеющий следующие параметры: импульсная мощность $2 \mathrm{~kW}$, дли- 


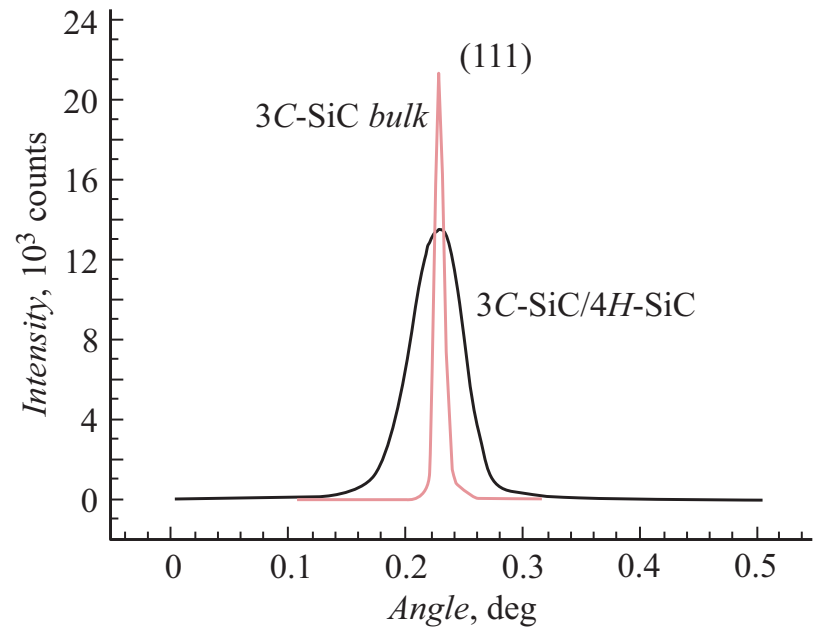

Рис. 1. Двухкристальные рентгеновские кривые качания, полученные от объемного монокристалла $3 C$-SiC и эпитаксиального слоя $3 C$ - $\mathrm{SiC}$, выращенного на подложке $4 H$-SiC сублимационным методом.

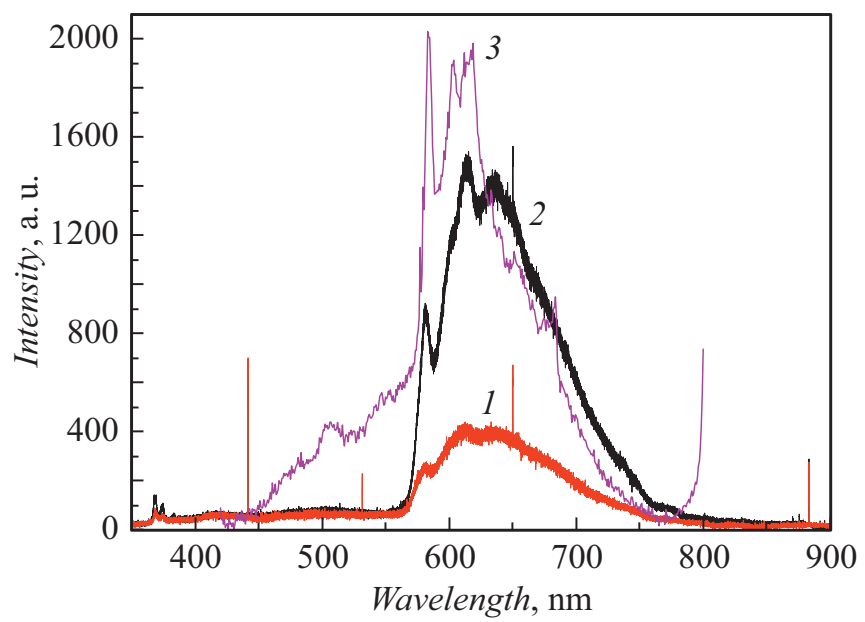

Рис. 2. Спектры ФЛ образцов $3 C$-SiC $\langle\mathrm{Al}\rangle$ при температурах $130(1), 80$ (2) и $4 \mathrm{~K}(3)$.

тельность импульса $10 \mathrm{~ns}$, частота повторения импульсов $100 \mathrm{~Hz}$. Плотность мощности накачки составляла $\sim 50 \mathrm{~kW} / \mathrm{cm}^{2}$. Исследования спектров ФЛ проводились в диапазоне температур 4-130 K.

Анализ рентгеновских топограмм образца показал, что слой $3 C$ - $\mathrm{SiC}$ образовался на всей поверхности эпитаксии $\left(\sim 1 \mathrm{~cm}^{2}\right)$ и имел мелкодвойниковую структуpy [1].

Для определения структурного совершенства эпитаксиального слоя применялся метод двухкристальной рентгеновской дифрактометрии. На рис. 1 представлены рентгеновские кривые качания образцов, выращенных на подложке $4 \mathrm{H}$-SiC. Наблюдавшаяся достаточно большая полуширина рентгеновской кривой качания, очевидно, связана с наличием DPB в эпитаксиальном слое $3 C-\mathrm{SiC}$.
В эпитаксиальных слоях $3 C$-SiC, легированных алюминием, наблюдался тот же спектр (ФЛ), что и в монокристаллах, легированных Al [9] (рис. 2). Интенсивность спектра быстро падала с повышением температуры.

Известно, что облучение $4 H$ - и $6 H-\mathrm{SiC}$ электронами, протонами и различными видами ионов приводило к росту интенсивности так называемой „дефектной“ фотолюминесценции (ДФЛ) [10-13]. ДФЛ наблюдалась также в монокристаллах и гетероэпитаксиальных пленках 3C-SiC, выращенных на кремнии, после облучения ионами $[14,15]$. Анализ экспериментальных результатов, полученных в работе [12], показал, что зависимость интенсивности ДФЛ от дозы облучения хорошо объясняется на основе предположения, что данная ФЛ обусловлена донорно-акцепторной рекомбинацией на паре азот-радиационный дефект.

$\mathrm{B}$ монокристаллах $3 \mathrm{C}$ - $\mathrm{SiC}$ после облучения электронами с энергией $0.9 \mathrm{MeV}$ и дозой $3 \cdot 10^{15} \mathrm{~cm}^{-2}$ наблюдалось появление полосы ФЛ с максимумом $\sim 650 \mathrm{~nm}$ (рис. 3). Эта полоса отсутствовала в спектре ФЛ исходного кристалла. В то же время в эпитаксиальных слоях облучение не приводило к появлению ФЛ в данном диапазоне энергий.

Согласно литературным данным, как ДФЛ, так и ФЛ в образцах $\mathrm{SiC}\langle\mathrm{Al}\rangle$ связаны с излучательной рекомбинацией на донорно-акцепторных парах, причем в обоих случаях в качестве доноров выступают атомы азота. В качестве акцептора в первом случае выступают атомы алюминия, а во втором - акцепторный центр неизвестной природы, предположительно структурный дефект.

Возможно, что при облучении образцов $3 C-\mathrm{SiC}$, имеющих DPB, часть образующихся структурных дефектов оседает на двойниковых границах (DPB), т.е. DPB являются геттерами образующихся при облучении структурных дефектов. В результате облучение не приводит к появлению ДФЛ в образцах $3 C$ - $\mathrm{SiC}$, имеющих DPB.

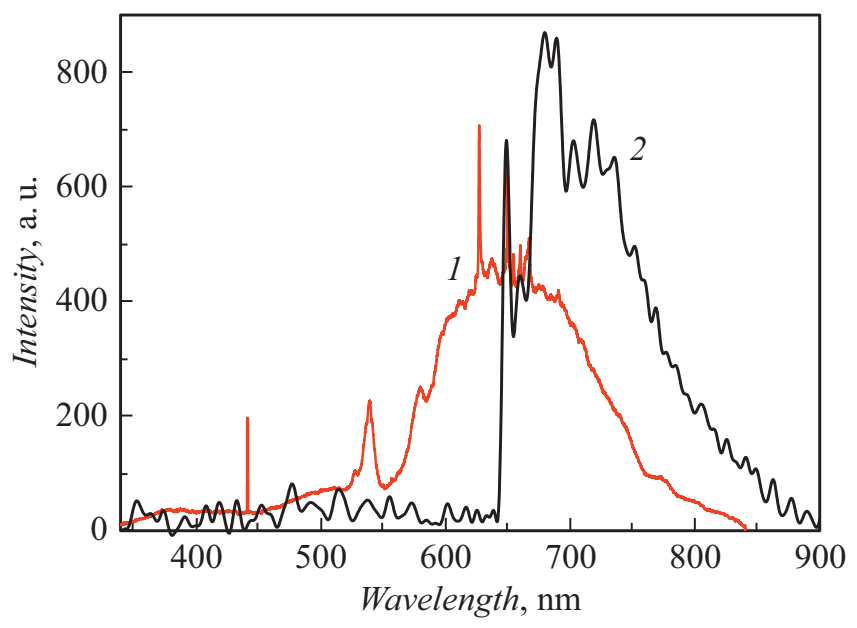

Рис. 3. Спектр ФЛ при $80 \mathrm{~K}$ для исходного монокристалла $3 C-\mathrm{SiC}(1)$ и образца, облученного электронами с энергией $0.9 \mathrm{MeV}$ и дозой $3 \cdot 10^{15} \mathrm{~cm}^{-2}(2)$. 
Это предположение согласуется с тем, что в образцах $3 C-\mathrm{SiC} / \mathrm{Si}$ и монокристаллах $3 C-\mathrm{SiC}$, где преобладают структурные дефекты других типов, наблюдалось появление ДФЛ после облучения.

Проведенное исследование показало, что существование в гетероэпитаксиальных пленках $3 C-\mathrm{SiC}$ границы двойников не сказывается на ФЛ, связанной с примесью алюминия. Однако в данных пленках не появляется характерная для карбида кремния ФЛ, связанная с радиационными дефектами. Возможно, это обусловлено тем, что имеющиеся в пленках структурные дефекты служат стоками для образующихся при облучении радиационных дефектов, являющихся компонентами донорноакцепторной пары, ответственной за данную ФЛ.

\section{Конфликт интересов}

Авторы заявляют, что у них нет конфликта интересов.

\section{Список литературы}

[1] Лебедев А.А., Мосина Г.Н., Никитина И.П., Савкина Н.С., Сорокин Л.М., Трегубова А.С. // Письма в ЖТФ. 2001. T. 27. B. 24. C. 57-63.

[2] Davydov D.V., Lebedev A.A., Tregubova A.S., Kozlovski V.V., Kuznetsov A.N., Bogdanova E.V. // Mater. Sci. Forum. 2000. V. 338-342. P. 221-224.

[3] Gorin S.N., Ivanova L.M. // Phys. Status Solidi B. 1997. V. 202. N 1. P. 221-245.

[4] Nishino S., Powell J.A., Will H.A. // Appl. Phys. Lett. 1983. V. 42. N 42. P. 460-462.

[5] Водаков Ю.А., Ломакина Г.А., Мохов Е.Н., Одинг В.Г. // ФTT. 1977. T. 19. B. 9. C. $1812-1814$.

[6] Lebedev A.A. // Semicond. Sci. Technol. 2006. V. 21. N 6. P. R17-R34.

[7] Лебедев А.А., Зеленин В.В., Абрамов П.Л., Богданова Е.В., Лебедев С.П., Нельсон Д.К., Разбирин Б.С., Щеглов М.П., Tрегубова A.C., Suvajarvi M., Yakimova R. // ФТП. 2007. T. 41. B. 3. C. 273-275.

[8] Jokubavicius V., Yazdi G.R., Liljedahl R., Ivanov I.G., Sun J., Liu X., Schuh P., Wilhelm M., Wellmann P., Yakimova R., Syvajarvi M. // Cryst. Growth. 2015. V. 15. N 6. P. 2940 2947.

[9] Suzuki A., Matsunami H., Tanaka T. // J. Electrochem. Soc. 1977. V. 124. N 2. P. 241-246.

[10] Макаров В.В., Петров Н.Н. // ФТТ. 1966. Т. 8. В. 5. C. 1602-1607.

[11] Кодрау Н.В., Макаров В.В. // ФТП. 1981. Т. 15. В. 7. C. 1408-1411.

[12] Lebedev A.A., Ber B.Ya., Seredova N.V., Kazantsev D.Yu., Kozlovski V.V. // J. Phys. D: Appl. Phys. 2015. V. 48. N 48. P. 485106.

[13] Козловский В.В., Лебедев А.А., Богданова Е.В., Середова Н.В. // ФТП. 2015. Т. 49. В. 9. С. 1198-1201.

[14] Макаров В.В. // ФТТ. 1967. Т. 9. В. 2. С. 596-600.

[15] Al Atem A.S., Ferrier L., Canut B., Chauvin N., Guillot G., Bluet J.-M. // Phys. Status Solidi C. 2016. V. 13. N 10-12. P. $860-863$. 